\title{
Functional Reserves of the Testosterone Synthesizing System in the Blood of Heifers in Different Breeds
}

\author{
V.I. Eremenko ${ }^{1}$ and E.G. Rotmistrovskaya ${ }^{2 *}$ \\ ${ }^{\text {I}}$ I.I. Ivanov Kursk State Agricultural Academy, Kursk, Russia \\ ${ }^{2}$ Kursk State Medical University, Kursk, Russia \\ *Corresponding author's Email: rotmistrovskaya.lena@mail.ru; (DORCID: 0000-0003-3515-3528
}

\begin{abstract}
The objective of this article was to investigate functional reserves of testosterone-synthesizing in the black-andwhite Holstein, Simmental, Aberdeen-Angus heifers, as well as cross-bred cows (Simmental $\times$ Aberdeen-Angus). To accomplish this goal the following tasks should be done: To conduct a comparative analysis of the data obtained between the experimental groups of heifers of different breeds, to carry out the functional stress tests of the testosterone synthesizing system in experimental heifers at the age of 6 months, to calculate the activity coefficients of the testosterone synthesizing system in experimental groups of heifers at the age of 6 months. The studies were carried out on black-and-white Holstein, Simmental, and Aberdeen-Angus heifers and their crossbred heifers (Simmental $\times$ Aberdeen-Angus). In order to determine the functional reserves of the testosterone synthesizing system, chorionic gonadotropin was intramuscularly administered at 6 months of age, and the activity of the testosterone synthesizing system was determined. The results of the effects of functional stress tests on the testosterone synthesizing system of the heifers indicated that the potential reserves of the testosterone synthesizing system in the Simmental and black-and-white breeds at the age of 6 months were lower than in Aberdeen-Angus and cross-breed animals. The 6-month-old Holstein and Simmental cattle had lower testosterone level relative to the compared groups of Aberdeen-Angus breed and crossbred animals. Functional reserves of the testosterone synthesizing system in experimental heifers at the age of 6 months in the group of Aberdeen-Angus heifers and in cross-breed animals were higher than the compared group. The activity coefficients of the testosterone synthesizing system were at the lowest level in the group of black-and-white and Simmental heifers.
\end{abstract}

Key words: Black-and-white Holstein, Functional reserves, Simmental, Testosterone, Testosterone synthesizing system

\section{INTRODUCTION}

To predict the future productivity of the animal, it is necessary to use not only individual indicators, which reflect only a short-term metabolic picture of the animal, but also a whole system of various indicators, which will expand the scientific understanding of the physiological characteristics of the predicted animals (Eremenko, 2010; Rexroad et al., 2019). The androgen system in females of cattle is poorly studied. Only, little information is published in related to androgens and meat quality in female livestock (Malekinejad and Rezabakhsh, 2015; Packer et al., 2018). So, the scientific literature has practically, no data on its functioning in productive farm animals.

It is known that, testosterone is one of the androgens that perform very important functions in the animal body (Zhang et al., 2008; French et al., 2013; Van Anders et al., 2015). In females, testosterone is produced in small amounts in the adrenal glands and ovaries (Dashukaeva and Nezhdanov, 1993; Dashukaeva, 1997). Also it well known, the level of the hormone in the blood does not always objectively reflect the real functional state of the gland, therefore, the functional reserves of the endocrine gland were determined using the method of functional stress tests, which allows setting the physiological limits of the functioning of the endocrine glands (Schlaff, 1986; Radchenkov, 2000).

In this regard, the task was to establish the pedigree features of the testosterone synthesizing system in 6-month-old heifers of different breeds for the introduction of chorionic gonadotropin. The objective of this article was to study the pedigree features of testosterone-synthesizing in the black-and-white Holstein, Simmental, Aberdeen-Angus heifers, as well as cross-bred cows (Simmental $\times$ Aberdeen-Angus). To achieve the set objective, it was necessary to solve the following tasks: To determine functional reserves of the testosterone-synthesizing system in experimental heifers of different breeds, to conduct a comparative analysis of the state of heifers of different breeds, and to calculate the activity coefficients of the testosterone synthesizing system in experimental groups of heifers.

\section{MATERIALS AND METHODS}

The black-and-white Holstein, Simmental, and Aberdeen-Angus heifers and crossbreeds of Simmental and AberdeenAngus breeds were studied in Kursk State of Russia. The animals randomly selected from Russian registered farms and 
were divided to four groups with 10 animals in each group. The animals had similar age (6-month-old). Animals were fed according to generally accepted norms that corresponded to their age and physiological state (NRC, 2001). To determine the functional reserves of the testosterone synthesizing system, heifers at the age of 6 months were intramuscularly injected with Chorionic Gonadotropin (CG) in a dose depending on the live weight of the animal. For determination of testosterone level Bovine Testosterone ELISA Kits (Biocompare, Inc, China) was used. Chorionic Gonadotropin was administered to heifers 3 times with an interval of 72 hours. The blood samples for testosterone were taken before the introduction of CG and 2, 12, 24, 48, and 72 hours after its administration.

The activity index of the testosterone synthesizing system was determined by the formula:

$\mathbf{I}_{\text {tsa }}=\mathbf{T 1}-\mathbf{T 0} / \mathbf{T 0}$, where

$\mathbf{I}_{\text {tsa }}$ - testosterone-synthesizing activity index

T0 - basal testosterone level before the first administration of CG.

T1 - testosterone level 24 hours after the third stress test with CG.

\section{Statistical analysis}

The One-way AOVA statistical method used for comparison of groups. For comparison of means, Duncan test was conducted in SAS software, version $10(\mathrm{P}<0.05)$.

\section{Ethical approval}

Experimental studies adopted by this experiment are in agreement with Principles of Ethics in Animal Research recognized by the Ivanov Kursk State Agricultural Academy, Russia.

\section{RESULTS AND DISCUSSION}

The study of testosterone in the blood of experimental heifers before the introduction of CG found that by the age of 6 months the concentration of this indicator in black-and-white Holstein and Simmental heifers was slightly lower than in the group of Aberdeen-Angus and crossbreed heifers. The concentration of testosterone in black-and-white heifers was $3.3 \pm 0.3 \mathrm{nmol} / \mathrm{L}$, in Simmental - $3.4 \pm 0.3 \mathrm{nmol} / \mathrm{L}$, in Aberdeen-Angus - $3.7 \pm 0.4 \mathrm{nmol} / \mathrm{L}$, and crossbred - $3.9 \pm 0.4$ nmol/L. There were no statistically significant differences between the experimental groups of heifers during this period $(\mathrm{P}>0.05)$. Considering that the maximum level of testosterone was at the age of 6 months, then during this period we conducted a stress test with CG. A detailed description of the administration of CG is described in the Materials and Methods section. After CG administration, testosterone levels gradually increased. The dynamics of testosterone in the blood of 6-month-old heifers after the first administration of CG is shown in figure 1.

The data shown in figure 1 indicated that two hours after the first administration of CG in the first group, the testosterone level was $4.6 \pm 0.4 \mathrm{nmol} / \mathrm{L}$, and in the second group $-4.4 \pm 0.4 \mathrm{nmol} / \mathrm{L}$, in the third group $-4.8 \pm 0.5$ $\mathrm{nmol} / \mathrm{L}$; in the fourth group $-4.7 \pm 0.4 \mathrm{nmol} / \mathrm{L} .12$ hours after the first administration of CG, there was a jump in the level of testosterone in the blood of heifers. In black-and-white Holstein heifers it was up to $5.1 \pm 0.5 \mathrm{nmol} / \mathrm{L}$, in Simmental breed up to $5.3 \pm 0.5 \mathrm{nmol} / \mathrm{L}$, in Aberdeen-Angus breed - up to $5.2 \pm 0.5 \mathrm{nmol} / \mathrm{L}$, in crossbreed animals up to $5.2 \pm 0.5$ nmol/L. 24 hours after the first administration of CG, an increase in the level of testosterone in the blood of heifers continued. The maximum testosterone level was observed in heifers of Simmental breed, it amounted to $6.2 \pm 0.5$ nmol/L. The hormone level in black-and-white and Aberdeen-Angus heifers was slightly lower - $6.0 \pm 0.6 \mathrm{nmol} /$. The lowest concentration of testosterone was in crossbreed animals - $5.6 \pm 0.4 \mathrm{nmol} / \mathrm{L}$. After 48 hours, the level of testosterone in the blood of heifers continued to increase and amounted to $6.4 \pm 0.5 \mathrm{nmol} / \mathrm{L}$ in the first group, and $6.6 \pm$ $0.4 \mathrm{nmol} / \mathrm{L}$ in the second group, $7.0 \pm 0.5 \mathrm{nmol} / \mathrm{L}$ in the third group, and $7.4 \pm 0.6 \mathrm{nmol} / \mathrm{L}$ in the fourth group.

The peak concentration of testosterone was detected 72 hours after the first administration of CG: in black-andwhite $-6.8 \pm 0.4 \mathrm{nmol} / \mathrm{l}$, in Simmental - $7.0 \pm 0.6 \mathrm{nmol} / \mathrm{L}$, in Aberdeen-Angus - $7.3 \pm 0.6 \mathrm{nmol} / \mathrm{L}$, and in crossbreed animals $-7.6 \pm 0.5 \mathrm{nmol} / \mathrm{L}$. To determine the maximum potential of the testosterone synthesizing system of experimental animals, the repeated administration of CG was carried out. Before the second administration of chorionic gonadotropin, the level of testosterone remained at the same level in 72 hours after the first stimulation. Dynamics of changes in blood testosterone of 6-month-old heifers after the second administration of CG is shown in figure 2.

As in figure 2 shown, two hours after the second administration of CG, the concentration of testosterone in blackand-white heifers was $6.9 \pm 0.5 \mathrm{nmol} / \mathrm{L}$, in Simmental - $7.2 \pm 0.5 \mathrm{nmol} / \mathrm{L}$, in Aberdeen-Angus - $7.8 \pm 0.7 \mathrm{nmol} / \mathrm{L}$, in cross-breeds $-8.2 \pm 0.4 \mathrm{nmol} / \mathrm{L}$. The highest concentration of hormone in the blood of heifers of both groups was observed 72 hours after the second administration of CG. The concentration of testosterone in black-and-white heifers was $7.8 \pm 0.5 \mathrm{nmol} / \mathrm{L}$, in Simmental $-8.3 \pm 0.6 \mathrm{nmol} / \mathrm{L}$, in Aberdeen-Angus - $9.6 \pm 0.5 \mathrm{nmol} / \mathrm{L}$, and crossbreed $-10.2 \pm$ $0.7 \mathrm{nmol} / \mathrm{L}$. Before the third stimulation, the level of blood testosterone in experimental animals was slightly higher in Aberdeen-Angus heifers $-9.6 \pm 0.5 \mathrm{nmol} / \mathrm{L}$. The dynamics of changes in testosterone in the blood of 6-month-old heifers after the third administration of CG presented in figure 3. 


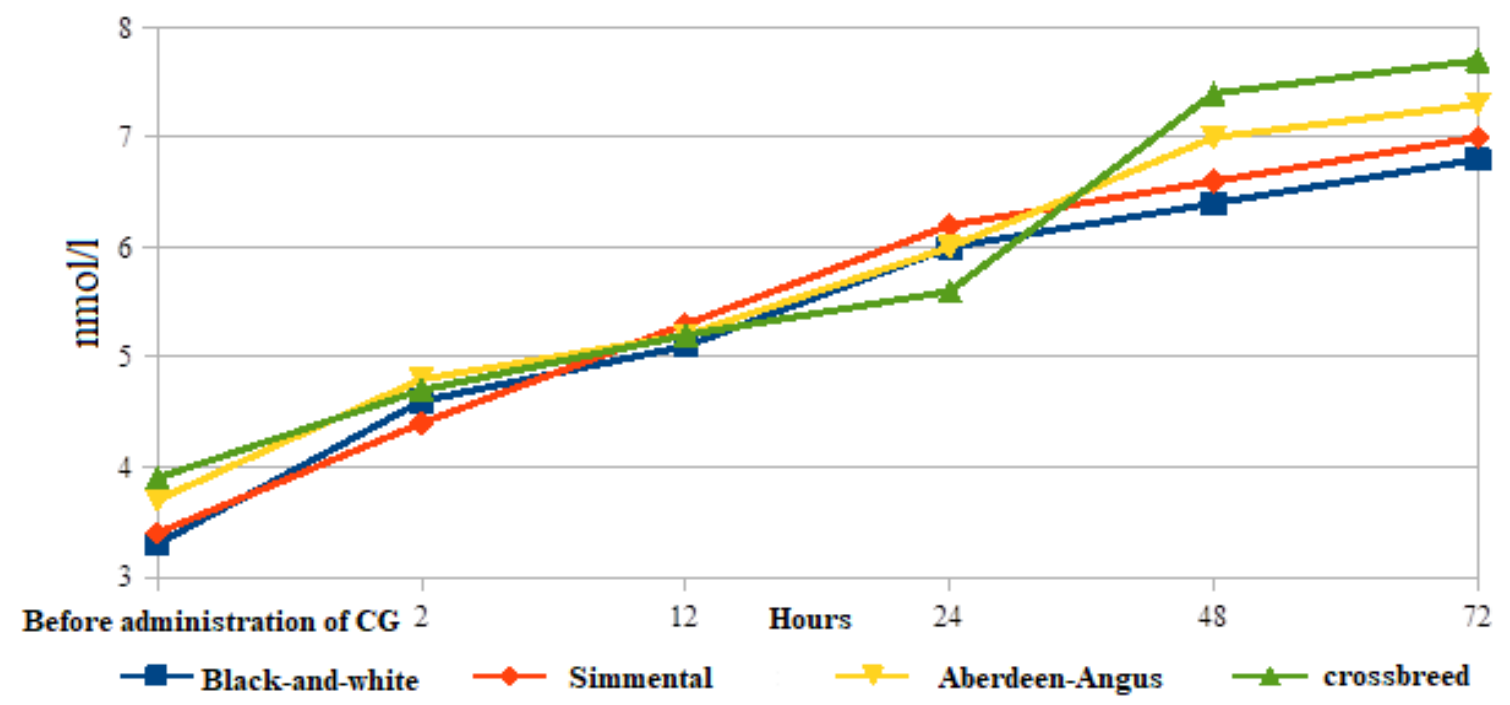

Figure 1. Dynamics of changes in blood testosterone of 6-month-old heifers after the first administration of chorionic gonadotropin.

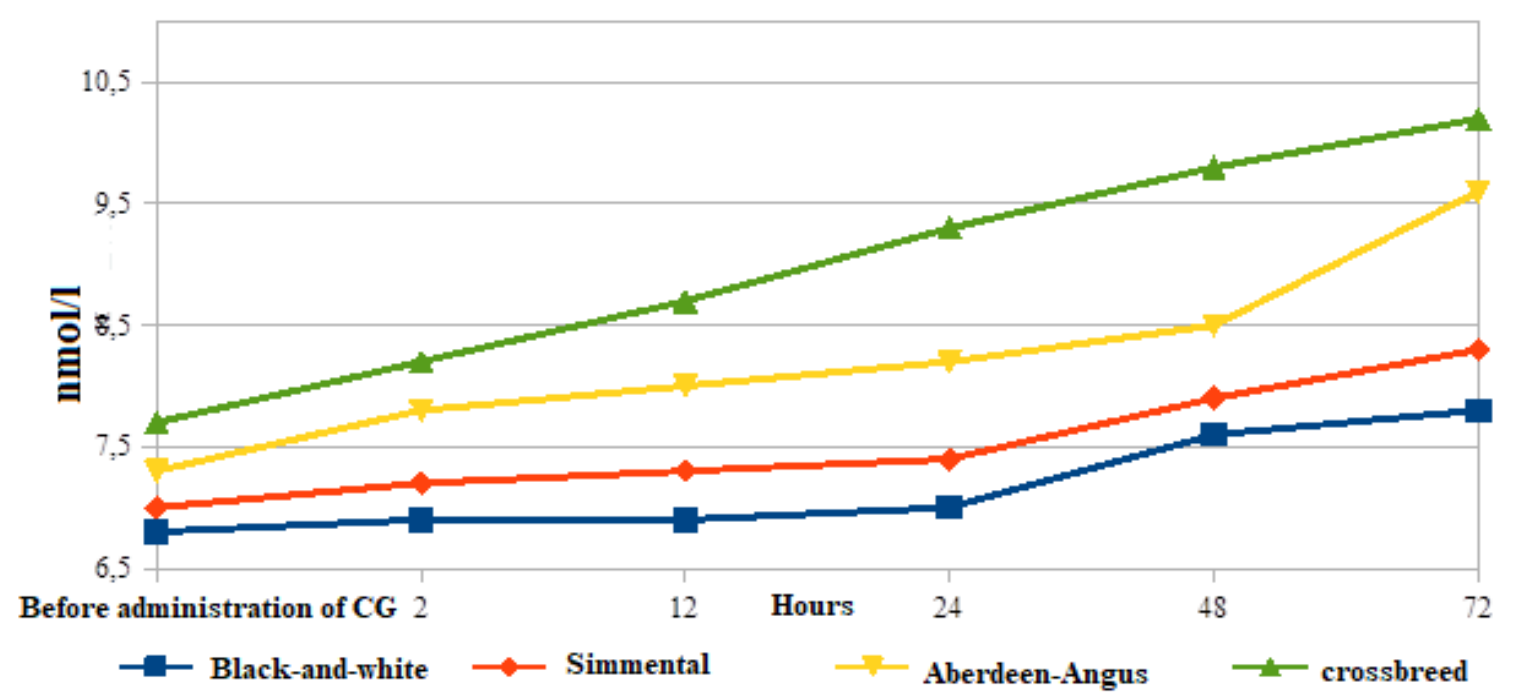

Figure 2. Dynamic changes in blood testosterone of 6-month-old heifers after the second administration of chorionic gonadotropin.

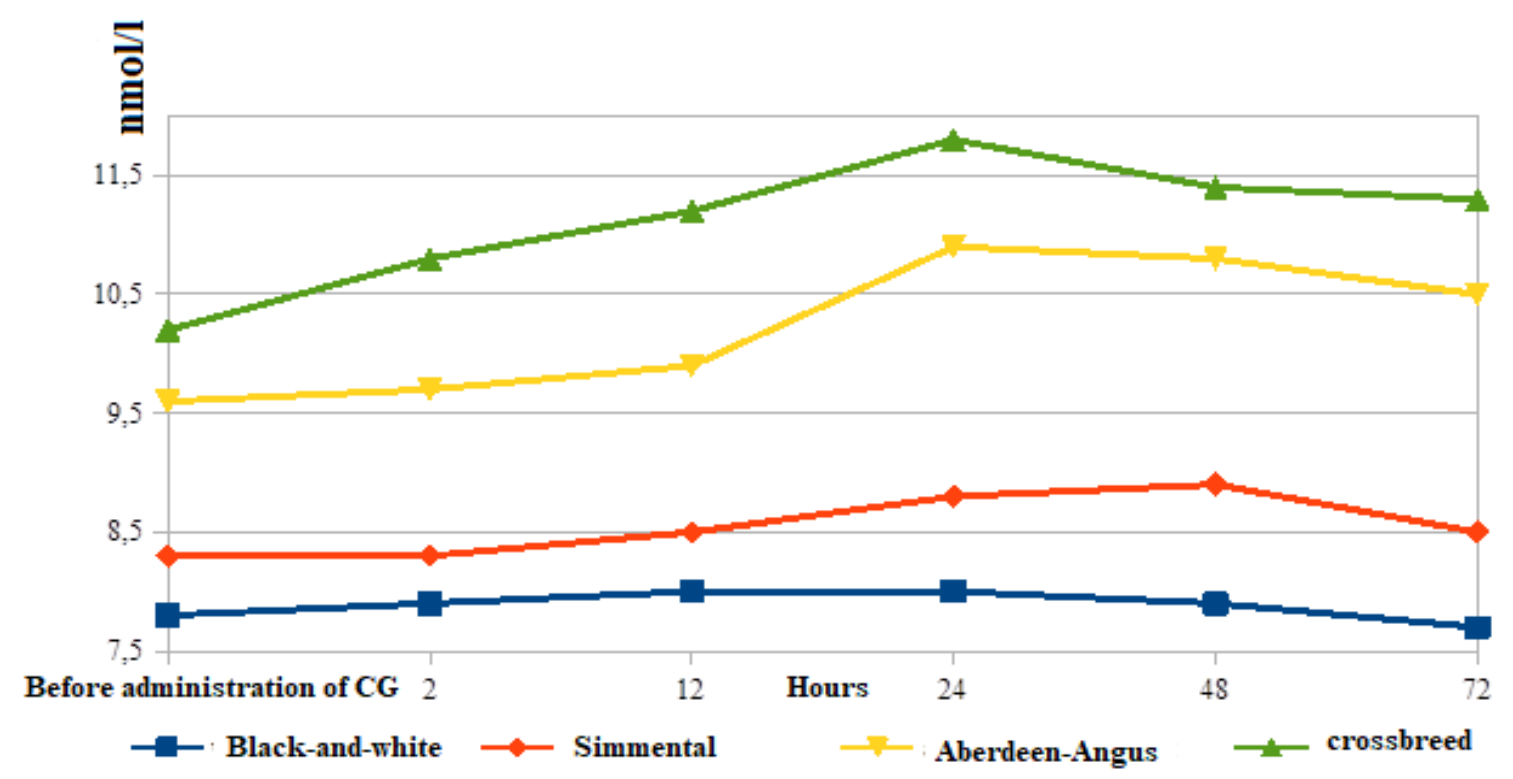

Figure 3. Dynamic changes in blood testosterone of 6-month-old heifers after the third administration of chorionic gonadotropin. 
After the third administration of CG, the reaction of the testosterone synthesizing system continued to increase, reaching its maximum in all groups after 24 hours. The concentration of testosterone in the blood of 6-month-old heifers after 3 injections of CG after 24 hours was $8.0 \pm 0.4 \mathrm{nmol} / \mathrm{L}$ in black-and-white heifers, in Simmental - $8.8 \pm 0.4 \mathrm{nmol} / \mathrm{L}$, in Aberdeen-Angus - $10.9 \pm 0.8 \mathrm{nmol} / \mathrm{L}$, and crossbreed - $11.8 \pm 1.0 \mathrm{nmol} / \mathrm{L}$. Subsequent administration of CG did not lead to an increase in testosterone in the blood but only maintained the achieved level of the hormone. The concentration of testosterone 24 hours after the third injection in the Aberdeen-Angus and crossbreed animals was statistically higher in comparison to the black-and-white heifers $(p<0.05)$. The concentration of testosterone 24 hours after the third injection in Simmental heifers with was significantly high respect to Aberdeen-Angus and crossbreed animals ( $p<0.05$ ).

After three stimulations, the concentration of testosterone in 6-month-old black-and-white heifers increased 2.3 times, in Simmental - 2.5 times, in Aberdeen-Angus - 2.8 times, in crossbreed animals - 2.9 times. The calculation of the activity index of the testosterone synthesizing system in 6-month-old black-and-white heifers was 1.42 , in the Simmental breed - 1.6, in the Aberdeen-Angus breed - 1.9, in the crossbreed heifers - 2.0. Thus, the performed functional stress test showed that the functional reserves of the testosterone synthesizing system in the Aberdeen-Angus heifers and in crossbreed animals have a higher index of activity of the testosterone synthesizing system than the black-and-white and Simmental heifers.

The difference in androgens levels in heifers is not reported exactly in an available published research. Whereas, the breed-related differences of the androgens in bulls was studied with Post and Bindon (1983) on Brahman cross and Hereford-Shorthorn in Australia. Findings of present study in about breed-related differences in androgen levels were in agreement with Post and Bindon (1983).

\section{CONCLUSION}

This study indicated the functional reserves of the testosterone synthesizing system in Aberdeen-Angus heifers and in crossbreed animals caused higher activity of testosterone synthesizing system than the black-and-white and Simmental heifers.

\section{DECLARATIONS}

\section{Authors' contributions}

All of authors had equal roles in writing, editing, and experimental process and finally checked and approved the last edition of article.

\section{Competing interests}

The authors have declared that no competing interest exists.

\section{REFERENCES}

Dashukaeva KG (1997). Change in hormonal status in cows during pregnancy; Stabilization of the agro-industrial complex in the market forms of management. interregional. Proceeding of Scientific Practice Conference of Young Scientists of Russia, Part 2. pp. 26-27.

Dashukaeva KG and Nezhdanov AG (1993). Hormonal changes in the mother-fetus system in cows, depending on their milk production and age. Agricultural Biology, 6: 72-76.

Eremenko VI (2010). Functional reserves of the endocrine system in predicting milk productivity. Kursk: Publishing house of Kursk State Agricultural Academy, Russia, p. 194.

French JA, Mustoe AC, Cavanaugh J and Birnie AK (2013). The influence of androgenic steroid hormones on female aggression in 'atypical' mammals. Philosophical Transactions of the Royal Society B: Biological Sciences, 368(1631): 20130084. DOI: https://doi.org/10.1098/rstb.2013.0084

Malekinejad H and Rezabakhsh A (2015). Hormones in dairy foods and Their Impact on Public Health. Iranian Journal of Public Health, 44(6):742-758. PMID: 26258087

National Research Council (NRC) (2001). Nutrient Requirements of Dairy Cattle. 7th revised ed. National Academy of Sciences, Washington, D.C.

Packer DT, Geesink GH, Polkinghorne R, Thompson JM and Ball AJ (2018). The impact of two different hormonal growth promotants (HGPs) on the eating quality of feedlot-finished steer carcasses. Animal Production Science 59, 384-394. DOI: https://doi.org/10.1071/AN17121

Post TB and BM Bindon (1983). Plasma luteinizing hormone and testosterone concentrations in different breeds of young beef bulls in the tropics. Australian Journal of Biological Sciences, 36: 545-549. DOI: https://doi.org/10.1071/bi9830545

Radchenkov VP (2000). Hormones, growth, and productivity of animals -Actual problems of biology in animal husbandry. Borovsk Publication, Borovsk, pp. 332-334. 
Rexroad C, Vallet J and Matukumalli LK (2019). Genome to Phenome: Improving Animal Health, Production, and Well-Being - A New USDA Blueprint for Animal Genome Research 2018-2027. Frontries in Genetics, 10:327. DOI: https://doi.org/10.3389/fgene.2019.00327.

Schlaff WD (1986) Dynamic testing in reproductive endocrinology. Fertility and Sterility, 45:589-606. DOI: https://doi.org/10.1016/S0015-0282(16)49328-3.

Van Anders SM, Steiger J and Goldey KL (2015). Effects of gendered behavior on testosterone in women and men. Proceedings of the National Academy of Sciences of the United States of America, 112(45): 13805-13810. DOI: https://doi.org/10.1073/pnas.1509591112.

Zhang JM, Konkle AT, Zup SL and McCarthy MM (2008). Impact of sex and hormones on new cells in the developing rat hippocampus: a novel source of sex dimorphism? European Journal of Neuroscience, 27(4):791-800. DOI: https://doi.org/10.1111/j.1460-9568.2008.06073. 